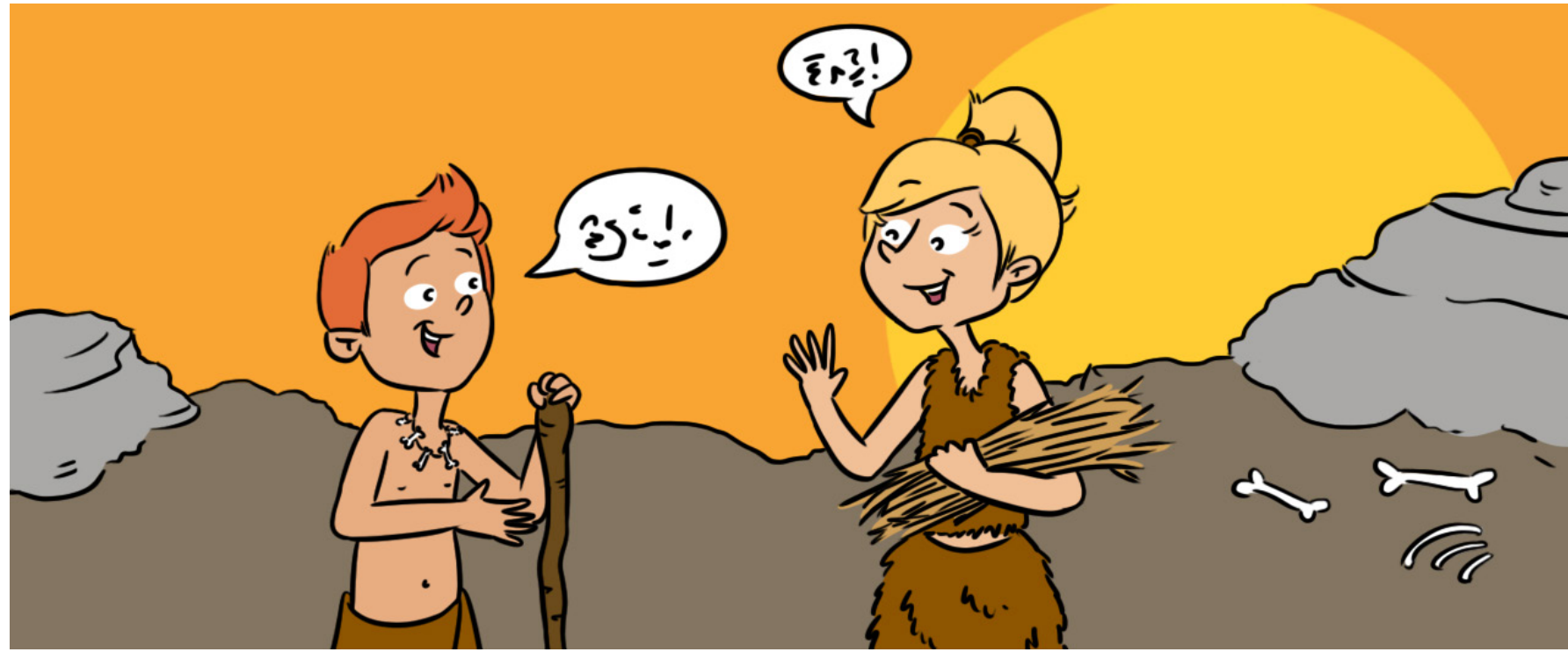

\title{
HOW PEOPLE SPOKE IN PREHISTORY
}

\section{Antonio Benítez-Burraco*}

Department of Spanish, Linguistics, and Theory of Literature, University of Seville, Seville, Spain

\section{REVIEWED BY: \\ INTER- \\ NATIONAL \\ BILINGUAL \\ SCHOOL AT \\ HSINCHU \\ TAIWAN \\ AGE: $15-16$}

\section{PREHISTORY}

The period between the use of first stone tools and the invention of the first writing systems.
How were languages spoken by our ancestors in prehistory? Because prehistory is the time before written records, we have no recordings or books from that period. Since time travel is not possible, linguists (scientists who study human languages) have come up with several ways of finding out how our ancient ancestors communicated. In this article, we explain these methods and what scientists have learned over the years about prehistoric languages. Our ancestors did not just grunt. On the contrary, they might have spoken languages as complex, or possibly more complex, than some present-day languages.

\section{INTRODUCTION}

Prehistory is defined as the period between the use of first stone tools and the invention of the first writing systems. Are you interested in prehistory? If you are, you surely know that our ancestors lived in caves, wore fur clothes, knew how to hunt big animals (like mammoths!), and were skillful enough to decorate the walls of their caves with wonderful paintings ... not to mention their superb abilities to make weapons, collect fruits and edible vegetables, and survive in an often cold and hostile environment full of dangerous animals, like cave bears or big hyenas. 
Even if you know tons of things about prehistory, perhaps you have never thought about which language your ancient ancestors spoke. English? A more ancient language, like Latin, the language of Romans? Hebrew, the language spoken by ancient Jews, like Noah? Or perhaps they just grunted. Or maybe they were able to communicate only with gestures, like many apes seem to do. How would you find out how prehistoric people communicated? This is a tough question, because we are talking about people living thousands of years ago. This is why almost nobody dares to make strong claims about the nature of prehistoric languages.

Imagine that you wanted to know something about the language spoken 100 years ago in your hometown. This would be easy! Old recordings may be available. And almost everywhere, you could find handwritten letters, newspapers, and books from that period. But what if you wanted to know how people form an earlier era spoke? What about Romans, for instance? Well, the Romans also left many written materials (poems, plays, and stories), as well as other interesting stuff, like graffiti, all of which enable us to know how the Romans used their language (Maximus was here, Brutus is stupid, I love Cornelia, and the like). But, if we go back even further, no cavemen were able to write yet, and no recording devices were available to fix their language. And of course, we have no time machine (yet) to travel to prehistory to see what it was like. So, we face a big problem.

The objective of this article is to show how linguists have still managed to figure out many things about the languages from prehistory. To achieve this knowledge, linguists have relied mostly (but not only) on the properties of present-day human languages, which they know very well.

\section{THE HISTORY OF LANGUAGES}

You have probably realized that languages change over time. They change slowly and subtly, but you may have noticed some of these changes. Your parents may use some old-fashioned words that you and your friends would never use. For example, if you want to say that something is really good, you may say dope or phat. Instead, your parents may say awesome or wicked ... and your grandparents, groovy or hip! However, it is not only the vocabulary that changes over time. All aspects of a language, from sounds, to grammar, to how words and sentences are used during conversation, change with time. Have you ever read the original version of any of Shakespeare's plays? If you have, you will have found many strange words and phrases. For instance, in Act 2, Scene 2 from Romeo and Juliet, Romeo praises Juliet's beauty by saying: "But wait, what's that light in the window over there? It is the east, and Juliet is the sun." However, what Shakespeare actually wrote (and what people from that period would have said) was: "But soft! What light through yonder window breaks? It is the east, and Juliet is the sun." Although almost everything in this 


\section{LANGUAGE CHANGE}

How words change in form and usage over time.

MOTHER

LANGUAGE

A language spoken in the remote past that changed over time and gave rise to different sister languages that are spoken nowadays (an example is Proto-IndoEuropean).

\section{LINGUISTICS}

The branch of science studying the structure of languages and how they are used for communicating.

\section{BORROWING}

The process by which sounds or words from a language pass into other language. quote is familiar, there is a strange word, yonder. Also, in present-day English, soft is an adjective and not a verb. If you go back in time even more, English starts to sound really strange. You may know the Our Father, one of the most famous Christian prayers. The first line says, "Our Father, who is in heaven." In the tenth century, people would have said instead "Fæder ure pu pe eart on heofonum." You probably cannot understand any of that, or even read some parts of it, because there are also unfamiliar letters, like æ or p. Actually, the tenth-century phrase above sounds more like German than like English. This is not strange, because German and English are related-they are called sister languages and have the same "mother," so to speak. This is why many German words are familiar to the English ear. Germans say Vater instead of father, and himmel instead of heaven. On the contrary, people speaking Romance languages (like Spanish), use words much less familiar to the speakers of English, like padre and cielo, respectively.

What is nice about the language changes that occur over time is that, when we compare different forms of English, in a sense we travel back into the past, to our parent's childhood, to Shakespeare's era, to the tenth century. And if we compare sister languages like English and German, we can go back even further, to the time when the mother language (called Proto-German) was spoken and neither English nor German existed yet. Over the years, linguists have learned that language changes take time and follow general rules (to learn more, read [1]). Using this knowledge, linguists can compare pairs of words with similar sounds and the same meanings in related languages, like German and English, and then infer how these words would have sounded some hundreds or even thousands of years ago (in Proto-German). If you think about it, this is some sort of time travel after all ... without a time machine! Linguists have discovered that most European languages like English and German, but also like Russian, Spanish, and Greek, are sister languages and belong to the same big family of languages, the Indo-European group (Figure 1). Linguists have also "reconstructed" the mother language that all these languages come from. It is called Proto-Indo-European and was spoken nearly 5,000 years ago!

Going back in time 5,000 years, with our "linguistic time machine" is an impressive achievement of linguistics! Unfortunately, the method is not perfect. Language change is not constant over time. For example, present-day Icelanders are able to read many of the Viking stories from the tenth century. The reason they can do this is that Icelandic has changed very slowly, compared with English, because Iceland is an isolated country. Can you imagine reading Beowulfor Chaucer's tales without the aid of a dictionary and tons of footnotes?

Another difficulty faced by linguists is that languages also change by borrowing words and sounds from other, unrelated languages. For example, notice that the English word pork is more similar to Portuguese porco, Romanian porc, or Spanish puerco, than it is to the German word for pork, Schwein. This seems 


\section{FIGURE 1}

This tree (from Fitch [2]) shows how the different languages that make up the Indo-European group are related to each other. The Indo-European group is a family of languages spoken in Europe and West Asia. At the base of the tree, you can see the Proto-Indo-European (the mother language of the group). The branches are the different language families (Germanic, Slavic, etc.). Present-day languages are displayed as the leaves of the tree.

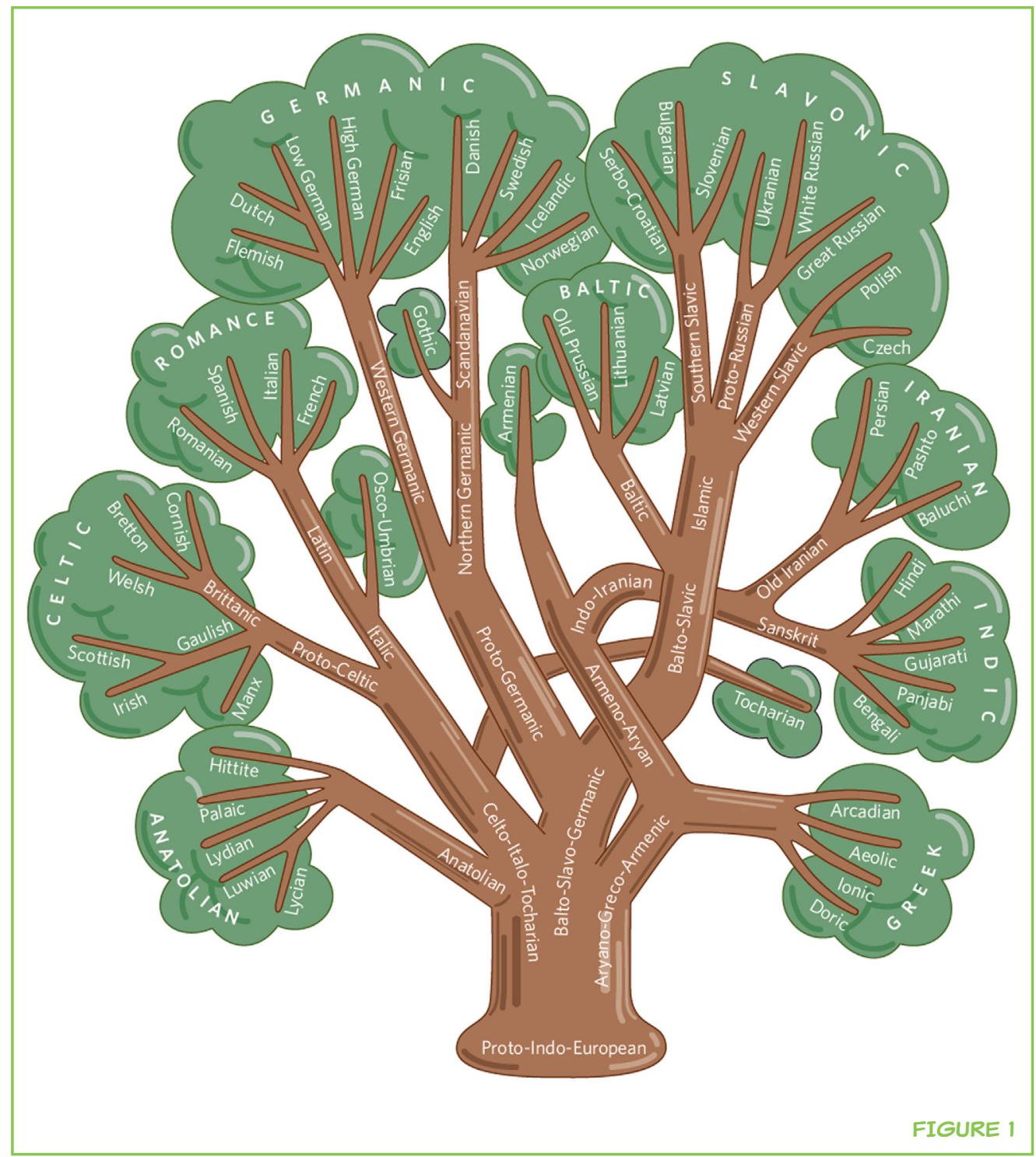

strange because, as noted earlier, English is more closely related to German than to romance languages like Portuguese, Romanian, or Spanish. How can we explain this? To solve this mystery, we need to look outside the language and see what happened with its speakers. In the eleventh century, England was conquered by the Normans. The Normans were the sons and grandsons of the Vikings that had previously settled in northern France. However, the Normans spoke French. In French, pork is said porc, and the English adopted that word. This borrowing of words, sounds, or grammatical rules happens worldwide and across all language families. Sometimes there is so much borrowing that it is impossible to figure out the actual origin of a language or their sister languages! This is a real problem for our time travel to prehistoric times. Because of borrowing, linguists cannot be confident about the features of any languages spoken more than 8,000-10,000 years ago. And this is well after most of our ancestors left their caves and started to cultivate plants and to build the first cities. 


\section{CULTURE}

The norms that regulate our life in society.

\section{GOING BACK IN TIME WITH THE AID OF SPEAKERS}

Does this mean that we will never know how our remote ancestors spoke? Not necessarily. Fortunately, linguists have found other methods to study prehistoric languages from more remote periods. After decades of study, linguists have concluded that all human languages are very similar. Of course, languages sound different (apple in English is manzana in Spanish) and the rules of grammar are different. However, they share many features: all languages have nouns and verbs, combine sounds into syllables to create new words, etc. Linguists think that the ultimate reason for these similarities is that languages are the product of the human brain and all of us have very similar brains (for an in-depth discussion, read [3]). What is more, we are now pretty sure that the brains of prehistoric people were not much different than ours, at least for the last 50,000 years. Looking at it this way, we should expect that all languages spoken in the past were similar to present-day languages.

Some linguists think that certain differences between languages can come from aspects of the culture or environment that are important for the people speaking them. For instance, if you live in a technologically advanced country, like the USA or Germany, your language will probably have many names of colors. However, in the languages spoken in some remote villages of $\mathrm{New}$ Guinea, there are only two words: dark and light. Linguists think this could be due to the fact that colors are important for industry or for clothing design. After all, it is really useful to have specific words for different colors if you need to talk about colors all the time! So, using information about the culture and environment that existed during prehistory, linguists might be able to predict some of the features of the languages spoken by prehistoric people.

Linguists have also started to use powerful computers to make massive comparisons between aspects of language known to vary across languages and dozens of other factors, like the places where their speakers live (deserts or forests?), the number of speakers (is it a world language like English, or does it have fewer than 100 speakers, like Mojave, a language from Arizona?), or how their speakers interact with other people (do speakers live in closeknit communities or do they talk with people speaking other languages on a daily basis?). The results are really interesting. It seems that languages can be influenced by all these factors. For instance, many languages, like Chinese or Thai, use tones (low versus high pitch) for distinguishing words (Figure 2A). Linguists have discovered that these tonal languages are mostly found in tropical regions, whereas tonal languages are unusual in temperate and cold areas (Figure 2B). This might be due to the effect of the cold, dry air on the vocal cords.

Linguists have also learned that languages with fewer native speakers and that are spoken by people who frequently interact with speakers of other languages usually share a set of common features, like fewer verb forms or fewer noun forms. Overall, their grammars are less complicated and easier 


\section{FIGURE 2}

A. In Chinese, if you pronounce ma with a rising tone (from low pitch to high pitch), the meaning is "hemp." But, if you use a falling tone (from high pitch to low pitch), the meaning is "to scold." B. Tonal languages are found throughout the world but are mostly located in tropical regions. Scientists think that this is because the vocal cords work worse in cold and dry environments (from Haspelmath et al. [4]).

\section{FIGURE 3}

The grammar of English is, at some points, less complicated than the grammar of German. See Box 1 for the explanation.

\section{BOX 1}

Detailed account of some differences between the grammars of English and German.

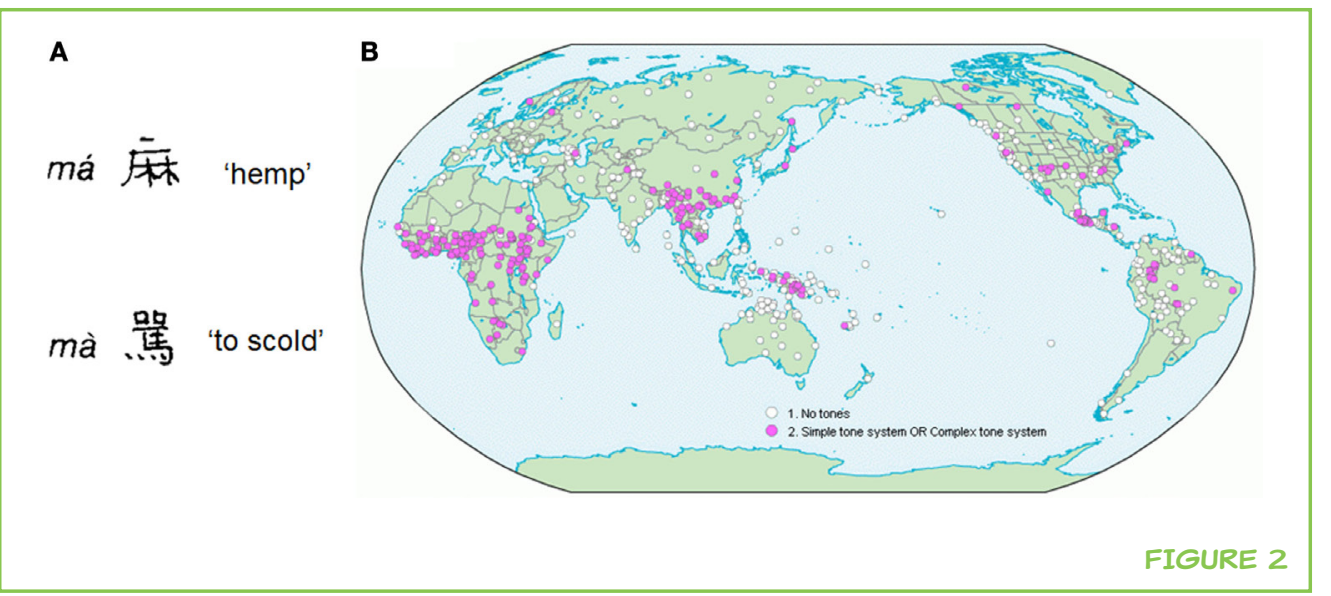

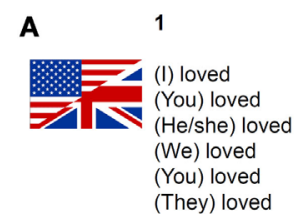

B

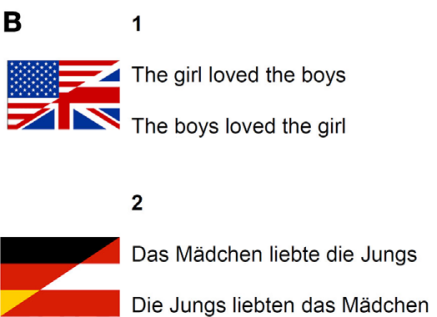

(Ich) liebte

(Du) liebtest (Er) liebte (Wir) liebten

(Sie) liebten

3

The boy loved the girl

The girl loved the boy

Der Junge liebte das Mädchen

Das Mädchen liebte den Jungen
FIGURE 3

A. English has fewer verb forms than German. (1) English has just one word form for the past of the verb play (played). (2). German has instead four different forms (liebte, liebtest, liebten, and liebtet). B. Knowing who is the doer in an English sentence is easier than in a German sentence. (1) The English sentences The girl loved the boys and The boys loved the girl mean exactly the opposite. The only difference between both sentences is how the words are arranged. The subject (who loved) is what stands before the verb. (2) The equivalent German sentences are, respectively, Das Mädchen liebte die Jungs and Die Jungs liebten das Mädchen. In the German sentences, the subjects also appear before the verbs, like in English. However, the verb has changed from singular to plural too (liebte/liebten). In other words, in German, the subject can be also identified because it agrees with the verb in number. (3) The English sentences The boy loved the girl and The girl loved the boy also mean exactly the opposite. Again, the only difference is word order: subjects (who loved) are placed before the verb, whereas objects (who are loved) are placed after the verb. (4) In the German versions, Der Junge liebte das Mädchen and Das Mädchen liebte den Jungen, the subjects also come before the verbs and agree with them in number, as in (2). However, a third interesting property of the German subjects is now evident: they have a distinctive word form (Junge), which contrasts with the form that the same noun has when it is the object of the sentence (Jungen). 
HUNTER-

\section{GATHERERS}

People who obtain most of their food supply by collecting wild plants and chasing wild animals. to learn by adults than the grammars of languages spoken by small groups of people who live more isolated. Are you studying German at school? Well, in the sense above, English is less complicated than German. German verbs have many more different forms than English verbs (Figure 3A). Also, in English, the subject of a sentence (the doer) has one distinctive feature only: it is usually found before the verb. But in German, it has three: it is usually placed before the verb, it exhibits a special word form, and it agrees in number with the verb (Figure 3B).

Overall, what linguists have discovered is that many factors not related to language itself, like cultural practices, number of speakers, ways of life, the physical environment, and many others, may affect aspects of language structure (for a good overview, read [5]). The good news for us is that archeologists (people studying cultural remains from the past) and paleoanthropologists (scientists who study human fossils) have achieved a good knowledge of how prehistoric humans lived. Using these data, we can try to figure out some things about the vocabulary and the grammar of these ancient languages. Because these cavemen lived in small communities of hunter-gatherers and had no regular contact with other similar communities, we can conclude that their languages might have been more complex than most of present-day languages. Obviously, this is just a rough picture. We will never know how to say mammoth in "cavemanese." We will never be able to translate Harry Potter novels into that language. But what we can know is better than nothing!

\section{CONCLUSION}

This is the end of our story (so far). It seems that some kind of time travel to prehistory is possible after all ... but only with the aid of a very special time machine: the linguistic time machine. We have learned that it is possible to understand some things about the languages spoken by our cavemen ancestors ... but have also learned that we will never know these languages in detail. But now, when you see other kids pretending to be cavemen and cave bears, you can be sure that only the bears communicated by grunting.

\section{ACKNOWLEDGMENTS}

I am deeply indebted to my sons, Antonio Benítez Tirado and Javier Benítez Tirado, for having inspired me to write this paper. The Spanish Ministry of Economy and Competitiveness is currently funding my research on language evolution (grant number FFI2016-78034-C2-2-P [AEI/FEDER,UE]). 


\section{REFERENCES}

1. Campbell, L. 1998. Historical Linguistics. Cambridge, MA: The MIT Press.

2. Fitch, W. T. 2007. Linguistics: an invisible hand. Nature 449:665-667. doi:10.1038/449665a

3. Moro, A. 2016. Impossible Languages. Cambridge, MA: The MIT Press.

4. Haspelmath, M., Dryer, S., Gil, D., and Comrie, B, editors. 2005. The World Atlas of Language Structures. Oxford: Oxford University Press.

5. Lupyan, G., and Dale, R. 2016. Why are there different languages? The role of adaptation in linguistic diversity. Trends Cogn. Sci. 20:649-660. doi:10.1016/j. tics.2016.07.005

SUBMITTED: 04 September 2017; ACCEPTED: 22 August 2018;

PUBLISHED ONLINE: 24 September 2018.

EDITED BY: Sabine Kastner, Princeton University, United States

CITATION: Benítez-Burraco A (2018) How People Spoke in Prehistory. Front. Young Minds 6:46. doi:10.3389/frym.2018.00046

CONFLICT OF INTEREST STATEMENT: The author declares that the research was conducted in the absence of any commercial or financial relationships that could be construed as a potential conflict of interest.

COPYRIGHT () 2018 Benítez-Burraco. This is an open-access article distributed under the terms of the Creative Commons Attribution License (CC BY). The use, distribution or reproduction in other forums is permitted, provided the original author(s) and the copyright owner(s) are credited and that the original publication in this journal is cited, in accordance with accepted academic practice. No use, distribution or reproduction is permitted which does not comply with these terms.

\section{REVIEWED BY}

\section{INTERNATIONAL BILINGUAL SCHOOL AT HSINCHU TAIWAN, AGE: 15-16} IBSH is a bilingual school (Mandarin and English) located in the "silicon valley" of Taiwan. The school focuses on equiping students with a cosmopolitan mindset, a rigorous science background, and a curious attitude. Many students are "IBSH Babies": a term coined for IBSH students who were schooled from Kindergarten through grade 12. Students continue to form tightly knit communities after graduation. 


\section{AUTHOR}

\section{ANTONIO BENÍTEZ-BURRACO}

I studied Biology and earned a PhD in biochemistry. But I was also interested in languages. During my studies, I managed to learn Russian (I love Russian writers from the nineteenth century), and soon decided to study Slavic languages in depth. Then, I realized that many scientists are interested in the biological basis of human language. Because I already had a strong background in biology, I decided to focus on this new field of research (nowadays called biolinguistics) and earned a second PhD in linguistics. Now, I do research to study how language is created at the level of the brain and how it has evolved in the human species. I teach at the University of Seville, in Southern Spain. *abenitez8@us.es 